\title{
EDITORIAL
}

\section{The Relationship Between Ski Patrols and Emergency Medical Services Systems}

The precise relationship between ski patrols and Emergency Medical Services (EMS) systems is a controversial topic. Ski patrols are represented by various organizations, including the National Ski Patrol (NSP), the Association of Professional Patrollers, and the Professional Ski Patrol Association. The NSP is the oldest and largest of these groups, with more than 28000 members and more than 600 affiliated ski areas (although that number may be decreasing with the current economy and area closures). The NSP is also the only ski patrol organization — and indeed one of the only nongovernmental Wilderness EMS (WEMS) groups whatsoever-with a specific federal charter for their work from the US government. The NSP is often associated with volunteer patrollers, but also has a professional division and is thus equipped to represent both volunteer and professional patrollers. ${ }^{1}$ The NSP also has the only training program uniquely tailored to the snowsport environment: Outdoor Emergency Care (OEC).

Ski area requirements for patrollers vary, but many ski patrollers operate under OEC Technician (OEC-T) certification through the NSP's OEC course-now in its fifth edition ${ }^{2}$ - with or without additional certifications. As this course has evolved and its scope widened, some now ask whether OEC-T certification can be used as an equivalent to traditional EMS certifications, both in terms of state certification and patient care. Traditional EMS certifications include Emergency Medical Technician (EMT), Emergency Medical Responder (EMR [recent changes in national EMS standards have converted the previous terminology of "First Responder" to "Emergency Medical Responder"3]), as well as wildernessspecific modifiers such as Wilderness First Responder (WFR) or Wilderness EMT (WEMT).

Further complicating the issue, some patrols utilize EMT certification in preference to OEC-T certification, ${ }^{4}$ while other patrols permit persons with medical training to exempt themselves from OEC certification altogether. ${ }^{5}$

In addition, with the assumption that the WEMS teams responding to backcountry rescues typically utilize traditional EMS certifications such as EMT or EMR for their healthcare providers, the question of who is best trained to respond to boundary areas such as "sidecountry" or ski area out-of-bound areas has been raised. ${ }^{6}$

Finally - and interestingly - the OEC-T curriculum is evolving to cover non-snowsport environments, and NSP is marketing it as the national standard for all types of outdoor care, not just snowsport-specific care. The National Ski Patrol states: "OEC has evolved to address the needs of other outdoor-based emergency care providers too, including wilderness medical technicians, river rafting and mountaineering guides, members of search and rescue groups, mountain bike patrollers, and parks and recreation employees. Today, OEC is considered the standard of training for emergency care in the outdoor environment." 7

In this issue of Wilderness \& Environmental Medicine, the study by Constance et al, "Prehospital medical care and the National Ski Patrol," addresses the certification and training aspect of these questions head on. The authors meticulously tabulate the hours, topics, skills, and information included in the EMR, EMT, and OEC curricula. They conclude that "the OEC-T curriculum includes a skill set and a fund of knowledge that exceed those of the EMR program, but does not include all the knowledge needed for an EMT program."

A number of points need to be made as this discussion continues in the wilderness medicine (WM), snowsport, and WEMS communities.

By joining a formal team, undergoing formal healthcare training and certification, wearing a uniform, patrolling a specific austere resource area on an established schedule, and notifying the public that they will be managing emergencies that arise there, ski patrollers have established a medical duty to act and meet the criteria to be considered EMS system providers. ${ }^{9,10}$ The National Association of State EMS Officials and the National Association of EMS Physicians have specifically identified ski patrollers as operational EMS providers who "should function within and not outside the mainstream healthcare system." "That is echoed in the ski patrol literature. A recent article in Ski Patrol Magazine asserts, "nationwide, ski patrols are known as an integral part of the EMS system."12 
Operating within a mainstream healthcare system includes an established scope of practice. Scope of practice is determined not only by education and certification (the topics addressed by Constance et $\mathrm{al}^{8}$ in this issue of Wilderness \& Environmental Medicine), but also by state licensure and credentialing as healthcare providers. For field providers, that scope of practice is laid out in the National EMS Scope of Practice Model. ${ }^{3}$ Providers without autonomous licenses (for example, EMTs) must be credentialed to operate under the license of an autonomous provider (for example, a physician). For any activities beyond first aid, systematically operating as field healthcare providers outside this structure could be seen to represent the practice of medicine without a licenseand Constance et $\mathrm{al}^{8}$ have established that OEC training and practice exceeds not only the first aid level of care, but even the level of EMR. Additionally, most medical authorities agree that ski patrols should be part of the EMS system and should operate accordingly, including meeting contemporary standards of medical credentialing and medical oversight. ${ }^{5,11,13-15}$ Even the OEC curriculum itself endorses this concept, stating in the fifth edition of the textbook that "ongoing medical oversight is the hallmark of quality health care and is the best method of ensuring that the treatment rendered by ski patrollers meets or exceeds both customers' expectations and the national education standards for emergency medical personnel."16(p36) The question, then, is this: why are so few ski patrollers working with the ongoing medical oversight of a state-sanctioned medical director, and operating within state EMS credentialing and licensure systems?

As in all aspects of EMS care, states vary in how they address the requirement to place all field healthcare providers within the established healthcare system. Pennsylvania, for example, recently passed legislation that identifies a category of operational EMS providers (such as tactical EMS teams and WEMS teams). ${ }^{17}$ The regulations attached to this legislation would have specifically credentialed patrollers as state-certified operational EMS providers, with the OEC curriculum specifically recognized as the scope of practice and a medical director providing licensure, credentialing, and quality improvement. Although the regulations went into place for tactical providers and other WEMS teams, lobbying efforts resulted in exclusion of ski patrollers from this regulation and any associated regulatory benefits or burdens.

Washington and Idaho proposed similar state regulatory solutions, and neither state ultimately passed them. ${ }^{4}$ In the case of Idaho, not only was the NSP not included in the EMS regulatory framework, but a new Act was introduced "relating to the unlicensed practice of medicine and the EMS system; amending ... Idaho Code to clarify an exception as it pertains to the Outdoor Emergency Care credential and standard of training provided by the National Ski Patrol System." "18 This Act expanded the definition of those without a specific medical license who may engage medical care. Originally this category included "a person rendering aid in an emergency, where no fee for the service is contemplated, charged or received." The expanded Act amended that statement to read: "This exception shall specifically include those individuals trained in and holding the outdoor emergency care (OEC) credential, as issued by the National Ski Patrol, Inc., while rendering aid in accordance with the standards of training of such credential, where no fee for the service is contemplated, charged or received." 18

This legislation passed and was put into law in July 2011, but not before an amendment was included limiting this exception to ski areas. ${ }^{19}$ Without this amendment, in theory, any volunteer rescue agency working in any environment could bypass state EMS oversight by utilizing OEC certification (which is now designed for all environments, not just ski environments) rather than EMS certifications. Nonetheless, even with the amendment, this legislation is notable. It grants privileges to practice volunteer medical care without traditional licensure or credentialing to a specific corporation, which is permitted to self-regulate and self-define what the scope of that medical care will be through a private, proprietary, and evolving curriculum (OEC).

In the same month as the new law was implemented in Idaho-July 2011-Maryland implemented new EMS regulations that also addressed the EMS-ski patrol issue. It became the only state of which I am aware that currently recognizes OEC as a certification specifically approved by state EMS protocol, and that specifically integrates OEC providers into the EMS regulatory system. ${ }^{20}$ As of 2007, no other states were reported to claim OEC as a state-recognized EMS certification to the National Association of State EMS Medical Officials. ${ }^{21}$

The original legislative/regulatory proposals seen in Pennsylvania, Washington, and Idaho might have afforded patrollers protection from civil liability and ensured that skills taught in OEC beyond the first aid level would not constitute unsupervised or unlicensed medical practice. They were advocated by some as an ideal solution to the question of OEC-EMS interface. ${ }^{22}$ Others, including NSP, have felt that this approach was not suitable. There are a number of arguments why formal inclusion in EMS systems was thought to be inappropriate. These include belief that the liability protection it offered was insubstantial, that the federal charter exempted patrollers from state regulation, that NPS can self-regulate with internal validation of their education, testing, and performance improvement, and that putative 
drawbacks to medical oversight and inclusion in an EMS system, especially involving external regulatory burden, overshadowed the putative benefits.

The NSP is taking steps to address the question of how medical oversight and field medical practice would be accomplished outside the formal EMS system. Currently, it has a Medical Associate membership category, intended to include volunteer physicians who assist with OEC training and general medical training of patrollers. The NSP is also currently working with the National Ski Area Association to draft a quality assurance guideline that could be used to develop medical quality assurance plans for their ski patrols, potentially involving physician-level medical oversight.

Other models have appeared, and may provide additional examples of ways to navigate the EMS-ski patrol relationship and ensure quality medical oversight and patient care.

As an alternative to inclusion into the state EMS system, some ski areas choose to insert preexistent EMS assets into their patrols on a site-specific basis (using the medical oversight and regulatory systems already in place for those EMS providers). For example, in Nevada, a study was done formally credentialing Advanced Life Support (ALS) providers as "ski patrol paramedics." This system provided for quality improvement processes and physician oversight required of EMS systems. The authors of that study found a more appropriate use of responding resources, acceptance by EMT-B ski patrollers initially skeptical of the system, and that in the 2010-2011 season, 10\% of the ski patrol patients received ALS care. ${ }^{23}$

Many areas already employ volunteer or paid physicians, who serve as medical directors or members of the ski patrol staff. However, if not actually serving as formal medical directors, there is some controversy as to whether patroller physicians should promote themselves to patients as physicians or as OEC-Ts when they are delivering care. This has patient care and liability ramifications for both the provider and the patrol, especially since physicians can never really disassociate themselves from their training and credentials, either in cognitive medical decision-making or in medicolegal defense. Some areas (primarily in the western portion of the country) even have on-site emergency clinics staffed by physicians.

There is also a potential resource problem. Even if we would like every ski patroller in the country to operate within an EMS system and under physician medical direction, EMS agencies in some areas are not equipped to handle this additional task. Also, few physicians have dual EMS-WM specialty credentials to provide this service. Certainly, physicians with other backgrounds can provide medical oversight. This has been done for years in traditional EMS, which was only recognized as a formal physician subspecialty in 2011. Indeed, emergency medicine is often practiced by physicians trained in other specialties, as there are not enough board-certified and residency-trained emergency physicians to staff even the nations' emergency departments themselves. ${ }^{24}$ But even finding and building relationships with qualified non-WM, non-EMS trained physician providers would be a challenge for some areas. It will be particularly hard to find dual EMS-WM trained physicians outside of the liability protection and infrastructure of the state EMS systems.

It is precisely this need that prompted the recent creation of the Wilderness EMS Medical Director Course, cosponsored by the National Association of EMS Physicians and the Wilderness Medical Society. ${ }^{25}$ Most wilderness medicine curricula for physicians do not emphasize EMS medical oversight, with rare exceptions such as the Carolina Wilderness EMS externship, ${ }^{26}$ the UCSFFresno emergency medicine residency and Wilderness Medicine/EMS fellowship, ${ }^{27,28}$ the University of Utah EMS/Wilderness Medicine fellowship, and the Wilderness EMS Institute's Wilderness Command Physician course. ${ }^{29}$ This is a challenge for the idea that all ski patrols should have a qualified medical director; however, it is an even bigger challenge to the idea that those medical directors can be readily found outside the preexisting EMS framework.

Looking further, there are many misconceptions that pervade the dialogue about medical oversight of ski patrollers and their relationship to EMS. One common misconception is that if "only" Basic Life Support (BLS) medical care is provided, medical oversight is not needed for a formal team providing field medical care. Contemporary standards of field medical care no longer support this concept. ${ }^{30}$ It is axiomatic among most field medical care specialists that quality BLS care is as important as quality ALS care, or perhaps even more important. ${ }^{31}$ This is true not only because quality ALS depends on quality BLS, but also because statistically most care rendered in the WEMS environment is at the BLS level, even when ALS is available. ${ }^{23,32}$ In addition, the distinction between ALS and BLS care has evolved; many of the skills now within the BLS scope of practice would have been ALS in the recent past. One need only survey controversies and changes in standard of care surrounding traction splints, ${ }^{33-36}$ suspension trauma, ${ }^{37-43}$ and spinal immobilization ${ }^{44-55}$ to recognize that there is a robust body of medical literature and a corresponding need for medical oversight for BLS as well as ALS activities.

Another common misconception in discussions of the interface between EMS and ski patrols is that inclusion 
in an EMS system will require additional training. Regulatory actions that have been proposed to include OEC in EMS systems, such as the Pennsylvania proposal, would not involve increased training time. That proposal accepted OEC as the training and certification standard without change. The only addition was physician oversight (to allow for credentialing and licensure, in compliance with medical law). A common anecdotal misperception was that OEC personnel would need to become EMTs or paramedics - that is not the case ${ }^{22}$ - and previous statements in the WM literature to the contrary have been retracted. ${ }^{56}$ As time goes by, would ski patrollers be required to meet other EMS requirements, like OSHA bloodborne pathogen or hazardous materials training? Possibly, but increasingly, these are standard for any responder, including other WEMS personnel such as search and rescue volunteers. Also, in my experience, these requirements are usually rolled into ongoing training schedules without extra training time. It is ethically difficult these days to defend not offering these trainings to either volunteer or professional field providers, as they are largely designed to protect the provider.

Another contested issue is the most appropriate training and certification configuration for treating patients in the snowsport environment. Constance et $\mathrm{al}^{8}$ compared training configurations involving OEC-T and traditional EMS certifications, but did not measure or study their efficacy in the practice environment. Numerous other training configurations and certifications are also available for WEMS teams responding to the snowsport environment. These include local training, "wilderness" modules added to traditional EMS certifications (WEMT, WFR, WFA), variously sourced Diplomas in Mountain Medicine, snowsport modules in other widely recognized certifications such as Prehospital Trauma Life Support, ${ }^{57}$ and multiple proprietary curricula offered by private wilderness medicine and rescue schools. The efficacy and practicality of various providers and certification types remains to be determined.

Clearly, all agree on the goal of improving the medical care rendered to wilderness area visitors and recreationalists. The study by Constance et $\mathrm{al}^{8}$ is an important contribution and clarifies the actual content offered by various certification program. Future research and position statements will help further clarify the optimal training and practice configuration for snowsport emergency medical care.

Let me conclude by sharing my own opinion. As in most areas of both EMS and wilderness medicine, the complexity and variety of operational environments confounds any single answer. I find it hard to argue that increased physician involvement, increased medical oversight, increased interoperability with traditional
EMS and other healthcare systems, and increased quality assurance is not a good thing for our snowsport patients. I also believe there is little face validity to the argument that any of these interventions will increase risk or insurance premiums - each of these interventions are used in other areas of healthcare to reduce risk and reduce insurance premiums.

Personally, I have a short-term and long-term perspective. In the short term, I am reminded of Voltaire, who two and a half centuries ago wrote "le mieux est l'ennemi du bien." In this case, I would paraphrase that to be "the best can be the enemy of the good." Would I want my family on a ski vacation to be cared for by certified and properly trained patrollers, operating within an EMS system and under the credentialing and quality management oversight of a licensed physician endorsed by the state to serve in this role? Sure. Is that a realistic standard for every ski area at this time? Probably not. Goodindeed excellent - care is delivered around the world by ski patrollers who work in systems that do not include all those elements. I am sympathetic to the argument that environments are individual, and that we should not let a national regulatory concept of "best" lead to the jettison of the "good," with the paradoxical result of decreased service and increased complexity. In some places, EMT certification may be best; in others, OEC; whereas in still others, combinations of both work well. Physicians may, and should, have varying levels and types of involvement in different ski areas.

But our obligation as healthcare professionals is to strive, whenever possible, for the best, not just the good, for our patients. In the long term, is the vision of certified and properly trained patrollers, operating formally within a state EMS system and under the credentialing and quality management oversight of a licensed EMS-WM physician, an appropriate goal? Absolutely. Is it realistic to think that, as EMS, WEMS, and ski patrols evolve, this goal is attainable at large and small ski areas across the country? Based on the high respect I hold for all of these communities of providers, I most certainly think it is.

\section{Seth C. Hawkins, MD, FAWM \\ Department of Emergency Medicine UNC-Chapel Hill School of Medicine Morganton, $\mathrm{NC}$}

\section{References}

1. Ski Patrol Magazine: 2011/2012 media kit. Available at: http://www.nsp.org/press/spm/spm_media_11-12.pdf. Accessed March 13, 2012.

2. McNamara EC. Outdoor Emergency Care. 5th ed. Boston: Brady; 2012. 
3. National Highway Traffic Safety Administration. National EMS scope of practice model. US Dept of Transportation; February 2007. Available at: http://www.nremt.org/nremt/ downloads/scope\%20of\%20practice.pdf. Accessed March 1, 2012.

4. Pietroski N. National Ski Patrol outdoor emergency care program. Wilderness Medicine. 2010;27:10.

5. Busko J. The concept of ski patrol medical direction. Available at: http://skipatrol.jonnathanbusko.com/ home.html. Accessed March 7, 2012.

6. Van Tilburg C. Sidecountry rescue-who should respond to ski resort out-of-bounds rescues? Wilderness Environ Med. 2010;21:100-102.

7. National Ski Patrol. Outdoor emergency care program. Available at: http://www.nsp.org/eduprograms/emergencycare.aspx. Accessed March 7, 2012.

8. Constance B, Auerbach PS, Johe DH. Prehospital medical care and the National Ski Patrol: how does Outdoor Emergency Care compare to traditional EMS training? Wilderness Environ Med. 2012;23:177-189.

9. Aehlert B, ed. "Wilderness EMS" in Paramedic Practice Today: Above and Beyond. St. Louis: Mosby-JEMS Elsevier; 2009.

10. Millin M, Hawkins SC, Smith W. "Wilderness EMS" in NAEMSP. Medical Oversight of EMS. Vol II. EMS Clinical Practice and Systems Oversight. Dubuque, IA: Kendall Hunt Professional, 2009.

11. National Association of EMS Physicians. Position statement: medical direction for operational EMS programs. Available at: www.naemsp.org/documents/ medicaldirectionforoperationalemsprograms.pdf. Accessed March 7, 2012.

12. Schopfer SE, Woolf D. Interoperability: the Post-9/11 buzzword. Ski Patrol Magazine. Winter 2009:16-17.

13. NAEMSP-WMS Wilderness EMS Medical Director. Course curriculum. Paper presented at: WMS Desert Medicine Conference; November 3-7, 2011; Tucson, AZ.

14. Warden C, Hawkins SC, Millin M, Bradley R. Medical direction of operational EMS programs: resource document to the NAEMSP position statement. Wilderness Environ Med. 2012;23:37-43.

15. Bennett BL. A time has come for wilderness emergency medical service: a new direction. Wilderness Environ Med. 2012;23:5-6.

16. National Ski Patrol. Emergency care systems. In: McNamara EC, Johe DH, Endly DA, eds. Outdoor Emergency Care. 5th ed. Upper Saddle River NJ: Prentice Hall; 2011.

17. Pennsylvania EMS Act 37 of 2009. Pennsylvania Dept of Health; 2009. Available at: www.portal.state.pa.us/portal/ server.pt?open $=514 \&$ objid $=556942 \&$ mode $=2$. Accessed March 13, 2012.

18. Legislature of the State of Idaho, 61st Legislature. Senate Bill no. 1021, first regular session; 2011. Available at: http://www.legislature.idaho.gov/legislation/2011/S1021. pdf. Accessed March 13, 2012.

19. Legislature of the State of Idaho, 61st Legislature. Senate Amendment to S.B. no. 1021, first regular session; 2011.
Available at: http://www.legislature.idaho.gov/legislation/ 2011/S1021A1.pdf. Accessed March 13, 2012.

20. Maryland Institute for Emergency Medical Services. Wilderness EMS protocols. Available at: http://www. miemss.org/home/linkclick.aspx?fileticket=_sov8_dbzc4\% 3d\&tabid=106\&mid=821. Accessed March 13, 2012.

21. National Association of EMS State Emergency Medical Services Officials. The training and certification of emergency medical services personnel; April 2007. Available at: http://www.nasemso.org/resources/monographs/ documents/training-certmonograph04-2007.pdf. Accessed March 13, 2012.

22. Millin MG. Ski patrollers and outdoor emergency care-a component of the healthcare system. Wilderness Medicine. 2011;28:6-7.

23. Smith BD. Bringing ALS to the mountain. EMS world; November 2011. Available at: http://www.emsworld.com/ article/10364382/bringing-als-to-the-mountain?page $=2$. Accessed April 16, 2012.

24. Ginde AA, Sullivan AF, Camargo CA. National study of the emergency physician workforce, 2008. Ann Emerg Med. 2009;54:349-359.

25. Hawkins SC. Wilderness EMS medical director course. Wilderness Medicine. 2012; 29:24.

26. Hawkins SC. The Carolina Wilderness EMS externship. American College of Emergency Physicians EMSprehospital care section newsletter; September 2011. Available at: http://www.acep.org/content.aspx?id= 81663. Accessed March 13, 2012.

27. UCSF-Fresno. UCSF-Fresno wilderness medicine/EMS fellowship. Available at: http://www.fresno.ucsf.edu/em/ wilderness/. Accessed March 7, 2012.

28. UCSF-Fresno. Emergency medicine. Parkmedic program: resident involvement. Available at: http://www.fresno. ucsf.edu/em/parkmedic/resident.html. Accessed March 7, 2012.

29. Wilderness EMS Institute. Wilderness command physician course curriculum. Available at: http://www.wemsi.org/ wcp-05.html. Accessed February 2, 2012.

30. Kuehl AE, Baker EF. Medical oversight. In: Kuehl AE, ed. Prehospital Systems and Medical Oversight. 3rd ed. Dubuque, IA: Kendall/Hunt, 2002:301.

31. Lehrfeld D, Fowler R. Resuscitation round table: five EMS experts offer views on key topic. J EMS. 2011;36:38-42.

32. Kaufman TI, Knopp R, Webster T. The Parkmedic program: prehospital care in the national parks. Ann Emerg Med. 1981;10:156.

33. Bledsoe BE, Barnes D. Traction splint: an EMS relic? J EMS. 2004;29:64.

34. Wilderness Medicine Institute of the National Outdoor Leadership School. Treatment principles; June 2008. Available at: https://rendezvous.nols.edu/content/view/ 1668/717/. Accessed February 23, 2012.

35. Dickinson ET. Distracting injuries mask serious symptoms; January 2011. Available at: http://www.jems. com/article/distracting-injuries-mask-seri. Accessed February $23,2012$. 
36. Schimelpfenig T. Femur traction splints are controversial. Available at: https://www.facebook.com/note.php? note_id $=10150266420721331$. Accessed February 23, 2012.

37. Pasquier M, Yersin B, Vallotton L, Carron PN. Clinical update: suspension trauma. Wilderness Environ Med. 2011;22:167-171.

38. Reinertson R. Suspension trauma and rhabdomyolysis. Wilderness Environ Med. 2011;22:286-287.

39. Mortimer RB, Wharton DR. Reply to suspension trauma and rhabdomyolysis. Wilderness Environ Med. 2011;22: 287-288.

40. Roggla G, Moser B, Roggla M. Suspension trauma. Emerg Med J. 2008;25:59.

41. Thomassen O, Skaiaa SC, Brattebo G, et al. Does the horizontal position increase risk of death following suspension trauma? Emerg Med J. 2009;6:896-898.

42. Adisesh A, Robinson L, Codling A, et al. Evidence-based review of the current guidance on first aid measures for suspension trauma. Health and safety executive research report RR 708, UK Health and Safety Executive, Birmingham; 2009. Available at: http://www.hse.gov.uk/ research/rrpdf/rr708.pdf. Accessed February 23, 2012.

43. Flora G, Margreiter R, Dittrich P, Stuhlinger W. Hanging tests-conclusion for the mountaineer. Paper presented at: Second International Conference of Mountain Rescue Doctors; November 18, 1972; Innsbruck, Austria.

44. Smith W. To backboard or not to backboard, that is the question? Selective spinal immobilization. Lecture, Colorado Symposium on Emergency Care; June 12, 2010. Available at: http://www.wildernessdoc.com/assets/ lectures/2010/spine\%20appendix \%20notes \%20csec\% 202010\%20smith.pdf. Accessed March 13, 2012.

45. Burton JH, Dunn MG, Harmon NR, Hermanson TA, Bradshaw JR. A statewide, prehospital emergency medical service selective patient spine immobilization protocol. J Trauma. 2006;61:161-167.
46. Burton JH, Harmon NR, Dunn MG, et al. EMS provider findings and interventions with a statewide EMS spineassessment protocol. Prehosp Emerg Care. 2005;9: 303-309.

47. Domeier RM, Frederiksen SM, Welch K. Prospective performance assessment of an out-of-hospital protocol for selective spine immobilization using clinical spine clearance criteria. Ann Emerg Med. 2005;46:123-131.

48. Domeier RM. Indications for prehospital spinal immobilization. National Association of EMS and Clinical Practice Committee. Prehosp Emerg Care. 1999;3:251-253.

49. Hauswald M, Ong G, Tandberg D, et al. Out-of-hospital spinal immobilization: its effect on neurologic injury. Acad Emerg Med. 1998;5:214-219.

50. Hoffman JR. Validity of a set of clinical criteria to rule out injury to the cervical spine in patients with blunt trauma. N Engl J Med. 2000;343:94-99.

51. Kwan I, Bunn F. Effects of prehospital spinal immobilization: a systematic review of randomized trials on healthy subjects. Prehosp Disast Med. 2005;20:47-53.

52. WHO Pre-Hospital Trauma Care Steering Committee. Spinal immobilisation for trauma patients. Cochrane Database Syst Rev. 2001;(2):CD002803. Updated July 2007.

53. Lekovic GP, Harrington TR. Litigation of missed cervical spine injuries in patients presenting with blunt traumatic injury. Neurosurgery. 2007;60:516-522.

54. Lowery DW, Wald MM, Browne BJ, et al. Epidemiology of cervical spine injury victims. Ann Emerg Med. 2001;38: 12-16.

55. Stroh G. Can an out-of-hospital cervical spine clearance protocol identify all patients with injuries? Ann Emerg Med. 2001;37:609-615.

56. Pietroski N. "Dr. Pietroski’s response." Wilderness Medicine. 2011;28:7.

57. National Association of EMTs. Prehospital Trauma Life Support. 7th ed. St. Louis, MO: Elsevier; 2011:477. 